\title{
High-dose-rate interstitial brachytherapy in early stage oral tongue cancer - 15 year experience from a tertiary care institute
}

\author{
Anshuma Bansal, MD, Prof. Sushmita Ghoshal, MD, Arun S Oinam, PhD, Suresh Chander Sharma, MD, \\ Bhaswanth Dhanireddy, MD, Prof. Rakesh Kapoor, MD \\ Department of Radiation Oncology. Post Graduate Institute of Medical Education and Research (PGIMER), Chandigarh, India
}

\begin{abstract}
Purpose: To determine outcomes of interstitial high-dose-rate brachytherapy (HDR-BT) in patients with early stage oral tongue cancer.

Material and methods: Ninety-two patients with stage I and II oral tongue cancer were treated with HDR-BT between 1999 and 2014: brachytherapy alone $=62(67.4 \%)$, and combination of external beam radiotherapy (EBRT) and brachytherapy $=30(32.6 \%)$. Median follow-up was 53.5 months. Patterns of failure, overall survival (OS), disease-free survival (DFS), local control rates (LCR), and nodal control rates (NCR) were determined.

Results: 5-year OS, DFS, LCR, and NCR were $73.2 \%, 58.2 \%, 64.2 \%$, and $83.8 \%$, respectively. In total, 43 patients $(46.7 \%)$ failed treatment: isolated local failures $=28(30.4 \%)$, isolated nodal failures $=8(8.7 \%)$, both local and regional failures $=7(7.6 \%)$. While in T1 stage, 5 year LCR were significantly higher in brachytherapy alone group compared to combined EBRT and brachytherapy group $(81.7 \%$ vs. $62.5 \%, p=0.04)$, the isolated nodal failure rates were not significantly different among the two groups. For T2 stage, NCR were higher in combined EBRT and brachytherapy group compared to brachytherapy alone $(92.9 \%$ vs. $74.3 \%)$. Acute mucositis (grade $\geq 2$ ) was seen more in brachytherapy alone group compared to the combined modality group ( $87 \%$ vs. $66 \%$ ), and this correlated significantly with the higher biological equivalent dose (BED) in the brachytherapy alone group.

Conclusions: Our study recommends treating patients with brachytherapy alone in T1 stage, and demonstrates the need for addressing nodal region either by neck dissection or nodal irradiation in T2 stage patients. Also, the study highlights the need for dose escalation (from the doses used in the study) in both T1 and T2 stage tumors when using interstitial brachytherapy either as sole modality or as a boost.

Key words: brachytherapy, high-dose-rate, escalation, oral tongue cancer.

\section{Purpose}

Interstitial brachytherapy is one of the standard curative treatments used in early stage oral tongue cancer and is favored over surgery in view of better functional preservation [1]. With surgery, 5-year local control rates in early stage oral tongue cancer have been reported to approximately $75-90 \%$ [2]. Interstitial implants also provide local control rates equivalent to that of surgery $[1,3]$. However, most of the results in literature have been described with continuous low-dose-rate brachytherapy (LDR-BT) $[4,5,6,7,8,9,10]$. With the evolution of afterloading techniques, high-dose-rate brachytherapy (HDR-BT) has replaced LDR-BT in most of the centers in the world. But with HDR, the results are variable $[7,11,12,13,14,15]$. The latest and largest experience of HDR-BT in early stage oral tongue cancers has been reported in 67 patients in a Japanese experience by Matsumoto et al. [14]. The major concern of treating these patients with brachytherapy alone is cervical lymph node metastasis, which has been reported in $20-50 \%$ of cases in literature $[2,5,16]$.

The aim of this retrospective study is to analyze the outcome and patterns of failure in patients with stage I and II oral tongue cancer who underwent interstitial brachytherapy with or without external beam radiation at our institute, and also, to find out whether our results correlated with those in literature in terms of local and nodal control rates. It is one of the studies, describing the clinical outcome of HDR-BT in early stage oral tongue cancer, in highest number of patients so far in literature.

\footnotetext{
Address for correspondence: Prof. Rakesh Kapoor, MD, Department of Radiation Oncology, Post Graduate Institute of Medical Education and Research (PGIMER), Sec12, Chandigarh, India, phone: +919872648344, 


\section{Material and methods}

\section{Patient's profile}

Ninety-two patients with histologically proven squamous cell oral tongue cancer were treated with HDR-BT at the Department of Radiotherapy and Oncology of our institute, between 1999 and 2014. The patients' characteristics are presented in Table 1. Only T1 and T2 tumors (American Joint Committee on Cancer, AJCC stage I and II) of the lateral border the oral tongue were included in this study. After biopsy confirmation of malignancy under anesthesia (which also helped in better defining the tumor dimensions), all patients underwent thorough clinical examination and contrast enhanced computed tomography (CECT) of the neck for staging of nodal disease. Only node negative patients were considered for brachytherapy.

\section{Treatment details}

Table 2 describes the treatment done for the patients. Out of 92 patients, 62 patients were treated by brachytherapy alone, and 30 patients were treated by combined external beam radiotherapy (EBRT) and brachytherapy boost. Among the 62 patients, 8 patients (T1 stage $=1$ patient and $\mathrm{T} 2$ stage $=7$ patients) had already undergone wide local excision and neck dissection as the primary treatment at some other institute, and due to focal margin positivity in the primary tongue region, were referred to

Table 1. Patient characteristics

\begin{tabular}{lc} 
Total number & $N=92$ \\
\hline Sex & \\
\hline Male & $65(70.7 \%)$ \\
\hline Age (years) & $27(29.3 \%)$ \\
\hline Median & 53 \\
\hline Range & $26-85$ \\
\hline Stage & $47(51.1 \%)$ \\
\hline \begin{tabular}{l} 
T1 \\
\hline T2
\end{tabular} & $45(48.9 \%)$ \\
\hline Type of tumor & $62(67.4 \%)$ \\
\hline Exophytic & $30(32.6 \%)$ \\
\hline Infiltrative & 47 \\
\hline Tumor length & $45(48.9 \%)$ \\
\hline$\leq 2 \mathrm{~cm}$ & \\
\hline$>2 \mathrm{~cm}$ & \\
\hline Tumor thickness & \\
\hline$<1 \mathrm{~cm}$ & \\
\hline$\geq 1 \mathrm{~cm}$ & \\
\hline
\end{tabular}

our institute for further treatment. All these cases were planned for interstitial brachytherapy (as radical treatment) for the primary site.

\section{Brachytherapy technique and dose}

The patients either underwent primary brachytherapy or EBRT to the dose of 40 Gy delivered in 20 fractions by parallel opposed fields, followed by brachytherapy boost. The brachytherapy procedure was performed under general anesthesia by "push and pull technique". The needles were inserted below the jaw and medial to the mandible and the plastic catheters were pulled retrogradely through the needles. For implantation, rules of the Paris system were followed [17], i.e. the needles were inserted in single or double plane, giving 5-10 mm margin from all clinically palpable disease. Double-plane was done for tumors with thickness more than or equal to $1 \mathrm{~cm}$. Additional buttons were used to improve the dose to the surface of the tongue. No spacer was used between the tongue and the mandible in accordance with the routinely followed institutional practice. Post procedure, patients treated before the year 2008 (47 patients), underwent two orthogonal $X$ rays for planning, while those treated in later years underwent a non-contrast $\mathrm{CT}$ scan for treatment

Table 2. Treatment characteristics

\begin{tabular}{|c|c|c|}
\hline Treatment & $\begin{array}{c}\text { Number } \\
\text { of patients } \\
n(\%)\end{array}$ & $\begin{array}{c}\text { Number } \\
\text { of patients } \\
\text { (stage wise) }\end{array}$ \\
\hline \multicolumn{3}{|l|}{ Brachytherapy } \\
\hline \multirow[t]{2}{*}{ As radical treatment alone } & $62(67.4 \%)$ & $\mathrm{T} 1=31$ \\
\hline & & $\mathrm{T} 2=31$ \\
\hline \multirow[t]{2}{*}{ As boost (to EBRT) } & $30(32.6 \%)$ & $\mathrm{T} 1=16$ \\
\hline & & $\mathrm{T} 2=14$ \\
\hline \multicolumn{3}{|l|}{ Brachytherapy technique } \\
\hline \multirow[t]{2}{*}{ Single plane } & $50(54.3 \%)$ & $\mathrm{T} 1=23$ \\
\hline & & $T 2=27$ \\
\hline \multirow[t]{2}{*}{ Double plane } & $42(45.7 \%)$ & $T 1=24$ \\
\hline & & $\mathrm{T} 2=18$ \\
\hline \multicolumn{3}{|l|}{ Neck addressal } \\
\hline \multirow[t]{2}{*}{ Neck not addressed } & $54(58.7 \%)$ & $\mathrm{T} 1=30$ \\
\hline & & $T 2=24$ \\
\hline \multirow[t]{2}{*}{ Neck addressed } & $38(41.3 \%)$ & $\mathrm{T} 1=17$ \\
\hline & & $\mathrm{T} 2=21$ \\
\hline \multirow{2}{*}{$\begin{array}{l}\text { Neck addressed by } \\
\text { neck irradiation (EBRT) }\end{array}$} & $30(32.6 \%)$ & $\mathrm{T} 1=16$ \\
\hline & & $\mathrm{T} 2=14$ \\
\hline \multirow{2}{*}{$\begin{array}{l}\text { Neck addressed by } \\
\text { neck dissection }\end{array}$} & $8(8.7 \%)$ & $\mathrm{T} 1=1$ \\
\hline & & $\mathrm{T} 2=7$ \\
\hline
\end{tabular}


planning (45 patients). The CT images were acquired on GE Light-Speed CT Scanner (GE Healthcare, Chalfont St. Giles, UK, a unit of General Electric Company) with slice thickness of $2.5 \mathrm{~mm}$. Treatment planning was done on the PLATO cancer treatment planning system (Elekta $\mathrm{AB}$, Stockholm, Sweden) before the year 2008, and on the Oncentra Master Plan ${ }^{\mathrm{TM}}$ v3.0 software Nucletron, an Elekta company (Elekta AB, Stockholm, Sweden) during and after the year 2008, where catheters were subsequently reconstructed and dose was prescribed to a point $5 \mathrm{~mm}$ outside the plane of the implant. The length of the catheters to be loaded was left to clinician's discretion, which would further determine the final volume of the implant. Patients were finally treated to a dose of 40-52 Gy at $4 \mathrm{~Gy} /$ fraction for primary brachytherapy treatment, and a dose of 18-24 Gy at 3 Gy/fraction when brachytherapy was used as a boost after EBRT. Two fractions per day were delivered with a minimum gap of six hours between the fractions. Treatment was delivered with iridium $\left({ }^{192} \mathrm{Ir}\right)$ using a remote controlled after-loading microselectron HDR classic machine (Nucletron, Elekta AB, Stockholm, Sweden) before the year 2008 and in later years, with microselectron HDR V3 machine (Nucletron, Elekta AB, Stockholm, Sweden). The brachytherapy source (iridium) strength ranged from 3.5 to 10 Curie. The doses for both brachytherapy and combined treatment plans were prescribed on the basis of ABS (American Brachytherapy Society) recommendations for HDR-BT for head and neck carcinoma, which has not adopted a standard dose fractionation schedule but recommends to keep dose per fraction for HDR-BT for oral cavity cancers to be below 6 Gy per fraction, to reduce the potential for long term morbidity [18]. The maximum dose limit to the mandible was however limited to $<2$ Gy per cubic centimeter without lead shielding, and the plans were optimized to reach this constraint.

\section{External beam radiotherapy dose}

Thirty patients received brachytherapy as a boost to EBRT. All these patients had infiltrative tumors. They were treated by parallel opposed lateral portals with either ${ }^{60} \mathrm{Co}$ gamma rays or $6 \mathrm{MV}$ photons and received $40 \mathrm{~Gy}$ in 20 fractions in 4 weeks to the primary and draining lymph nodes. Neck nodes were treated electively in all these patients. In 2 patients (both stage T2 with poorly differentiated histology) who were planned with chemoradiation, concurrent single agent cisplatin, $100 \mathrm{mg} / \mathrm{m}^{2}$ intravenously was administered on days 1 and 22 of the radiation schedule after proper hydration.

\section{Follow up}

Median follow up was 53.5 months (range 6-183 months). The first clinical follow up was scheduled at 2 weeks after brachytherapy, and patients were monitored for mucosal reactions using Common Terminology Criteria for Adverse Events version 4.0 (CTCAE v 4.0). Thereafter, follow up was done by clinical examination every two months for the first year and then quarterly. Contrast enhanced computed tomography of the neck and chest $X$-rays were obtained at 6 months intervals. Recurrence at local or nodal site was considered as local or nodal failure from day zero. Fine needle aspiration cytology or a biopsy was carried out to document a recurrence in clinically suspicious cases.

\section{Statistical analysis}

In this retrospective study, frequency tables with counts and percentages were used to describe pre-treatment and treatment characteristics of the patients. The case records of the patients were reviewed to determine patterns of failure. Survival and control rates were calculated by the Kaplan-Meier method and examined for significance with a log-rank test. The Cox proportional hazard model was used for multivariate analysis. Pearson's method was used to find the correlation between the acute and late toxicities and the biological equivalent dose (BED). The conventional $p 0.05$ level was considered significant. Data were analyzed using the statistical software SPSS for Windows (version 19.0).

\section{Results}

\section{Pattern of failure}

At 53.5 months of median follow up period, 43 patients $(46.7 \%)$ failed treatment. Table 3 shows the pattern of failure among these patients and the stage to which they belong. No distant metastasis was observed as the first event of failure. The median time to local and nodal failure was 22 months and 13 months, respectively.

\section{Local control and survival}

The median follow up time was 53.5 months (range 6-183 months). One-, 3-, and 5-year overall survival (OS),

Table 3. Pattern of failure

\begin{tabular}{|c|c|c|c|}
\hline Failure type & $\begin{array}{c}\text { Number of patients } \\
\text { failed (\%) }\end{array}$ & $\begin{array}{c}\text { Stage wise failures/ } \\
\text { Stage number of patients failed }\end{array}$ & $\begin{array}{l}\text { Number of patients } \\
\text { who received EBRT }\end{array}$ \\
\hline \multirow[t]{2}{*}{ Local } & 28 (30.4\%) & $\mathrm{T} 1 / 11$ & 5 \\
\hline & & $\mathrm{T} 2 / 7$ & 5 \\
\hline \multirow[t]{2}{*}{ Lymph nodal } & $8(8.7 \%)$ & $\mathrm{T} 1 / 4$ & 0 \\
\hline & & $\mathrm{T} 2 / 4$ & 0 \\
\hline \multirow[t]{2}{*}{ Local + lymph node } & $7(7.6 \%)$ & $\mathrm{T} 1 / 3$ & 3 \\
\hline & & $\mathrm{T} 2 / 4$ & 1 \\
\hline
\end{tabular}

EBRT - external beam radiotherapy 

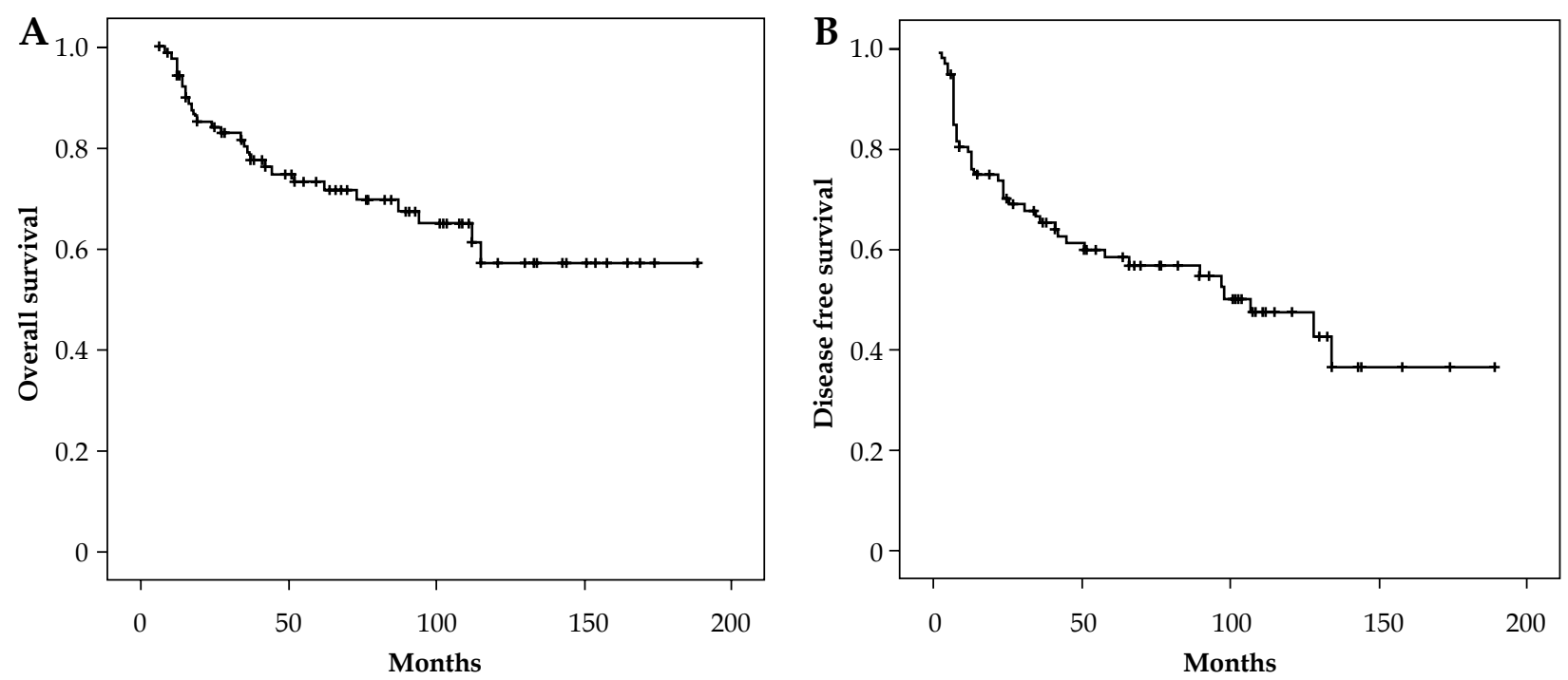

$\neg$ Survival function $\quad+$ Censored
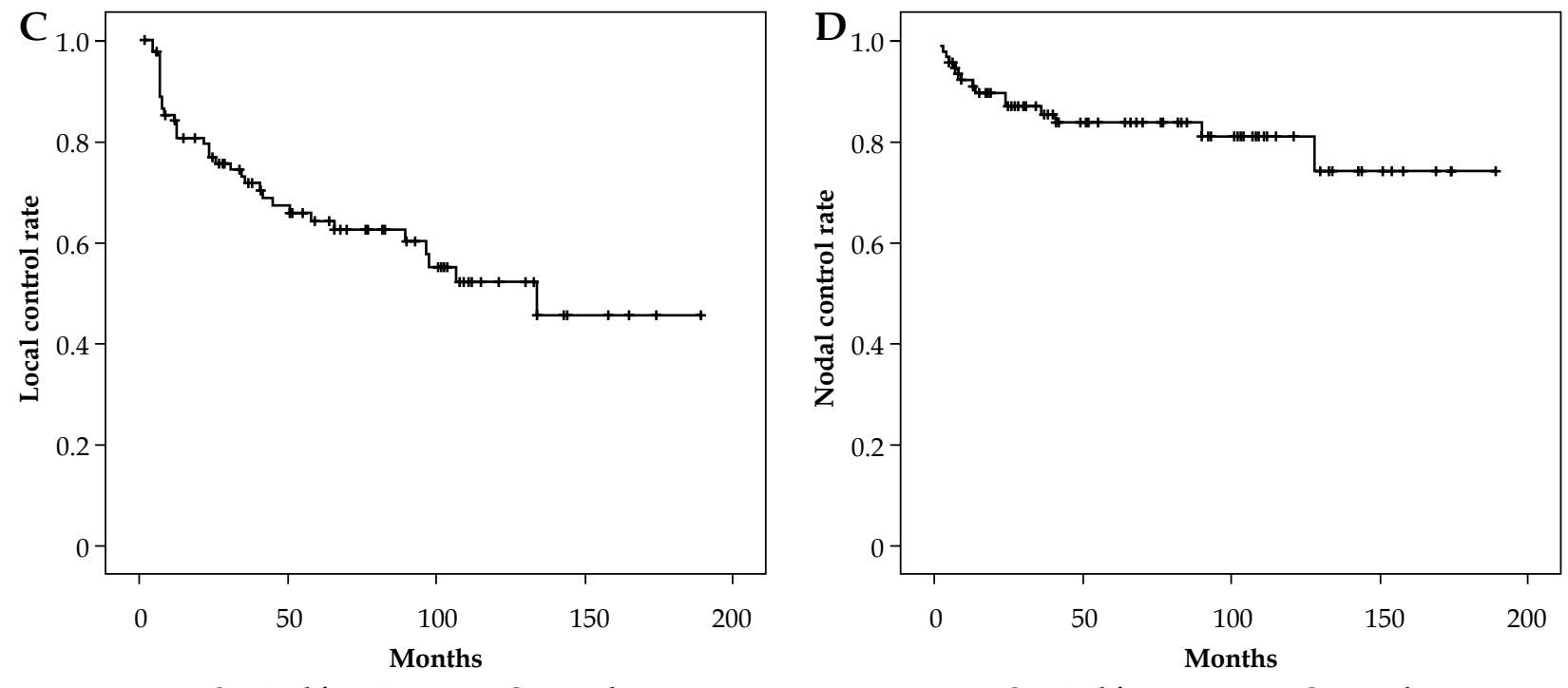

Fig. 1. A) Overall survival rates. B) Disease-free survival rates. C) Local control rates. D) Nodal control rates

disease-free survival (DFS), local control rates (LCR), and nodal control rates (NCR) were $97.8 \%, 79 \%$, and $73.2 \% ; 79.2 \%, 65.2 \%$, and $58.2 \% ; 84.1 \%, 71.7 \%$, and $64.2 \%$; and $92.1 \%, 85.4 \%$, and $83.8 \%$, respectively (Figure $1 \mathrm{~A}-\mathrm{D})$.

\section{Control rates and survival rates according to stage (Figure $2 A, B$ )}

The 5 year LCR for stage 1 and 2 were $74.7 \%$ and $52.5 \%$, respectively, which is statistically significant $(p=0.04 ; \mathrm{HR}=0.50,95 \% \mathrm{CI}: 0.25-0.99)$. Also, the 5 year DFS for stage 1 and 2 were $69.5 \%$ and $45.5 \%$, respectively, which is again statistically significant $(p=0.04$; $\mathrm{HR}=0.54,95 \%$ CI: 0.29-1.006). The difference in OS between the two stages, however, could not reach significance at $5 \%$ level of probability $(p=0.2)$.

\section{Control rates and survival rates according to prior external beam radiotherapy to local and nodal site}

Patients treated with EBRT and brachytherapy as boost, had poor local control rates and survival rates, compared to those treated with brachytherapy alone but the nodal failures were less in the prior group of patients. The difference was however not statistically significant (Table 4).

Considering the fact that patients treated with combined modality might have higher stage compared to those treated with brachytherapy alone, we compared the control rates and survival rates between patients treated with brachytherapy alone and those treated with EBRT and brachytherapy boost by T stage (Table 5).

We found that for T1 stage, 5 year LCR was significantly higher in patients treated with brachytherapy alone 

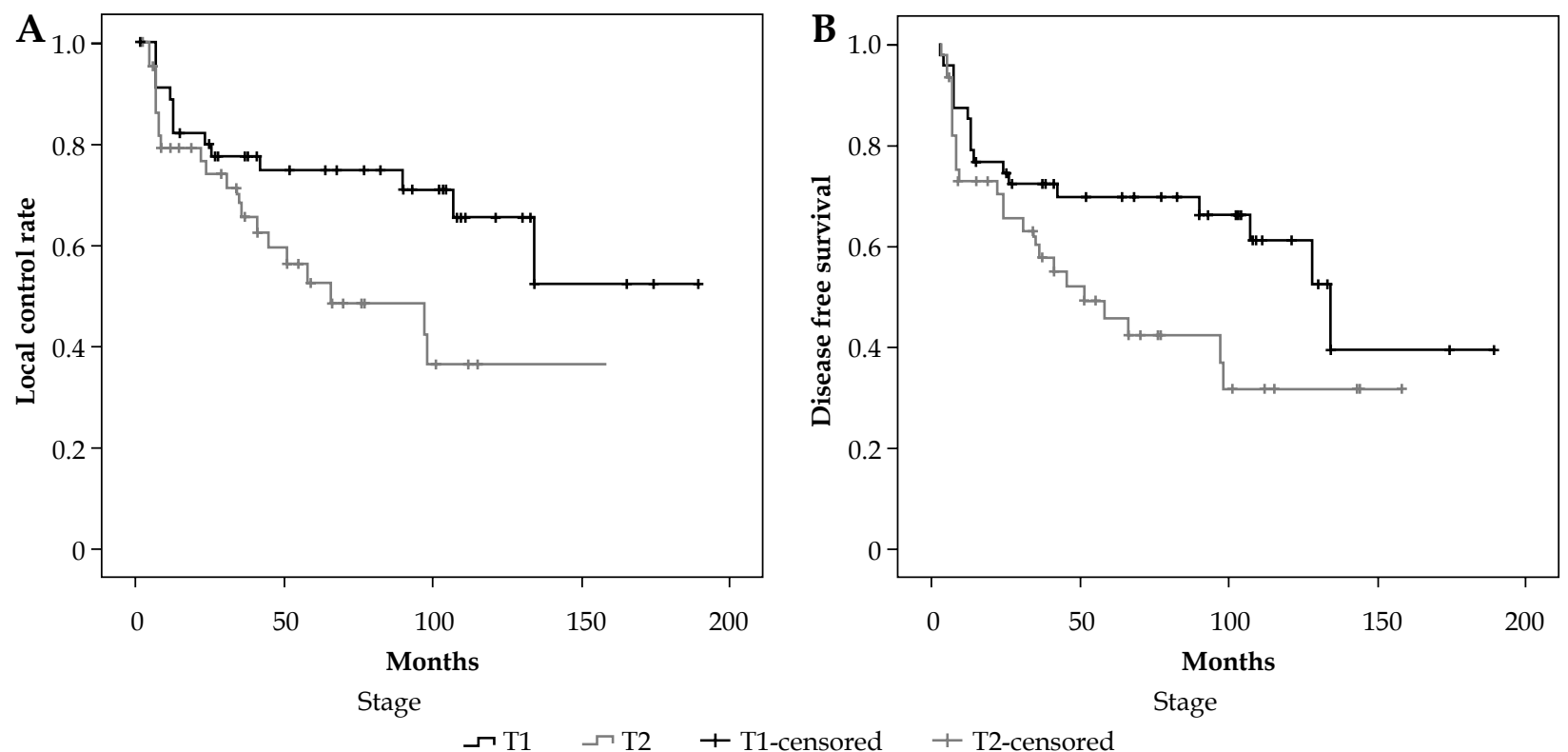

Fig. 2. A) Local control rates according to stage. B) Disease free survival rates according to stage

Table 4. Control rates and survival rates in patients treated by brachytherapy alone or as a boost

\begin{tabular}{lccc} 
& $\begin{array}{c}\text { Brachytherapy alone } \\
(n=62)\end{array}$ & $\begin{array}{c}\text { EBRT + brachytherapy boost } \\
(n=30)\end{array}$ & $p$ \\
\hline 5 year local control rate & $68.2 \%$ & $57.6 \%$ & 0.06 \\
\hline 5 year nodal control rate & $82.1 \%$ & $87.6 \%$ & 0.83 \\
\hline 5 year disease free survival & $59.3 \%$ & $57.6 \%$ & 0.45 \\
\hline 5 year overall survival & $78.8 \%$ & $61.1 \%$ & 0.09
\end{tabular}

EBRT - external beam radiotherapy

Table 5. Control rates and survival rates in patients treated by brachytherapy alone or as a boost in relation to T stage

\begin{tabular}{lcccccc} 
& \multicolumn{3}{c}{ T1 $(n=47)$} & & T2 $(n=45)$ \\
\cline { 2 - 8 } & $\begin{array}{c}\text { Brachytherapy } \\
\text { alone } \\
(n=31)\end{array}$ & $\begin{array}{c}\text { EBRT }+ \\
\text { brachytherapy boost } \\
(n=16)\end{array}$ & $p$ & $\begin{array}{c}\text { Brachytherapy } \\
\text { alone } \\
(n=31)\end{array}$ & $\begin{array}{c}\text { EBRT }+ \\
\text { brachytherapy boost } \\
(n=14)\end{array}$ & $p$ \\
\hline 5 year local control rate & $81.7 \%$ & $62.5 \%$ & 0.04 & $56.4 \%$ & $51.9 \%$ & 0.16 \\
\hline 5 year nodal control rate & $90.5 \%$ & $85.1 \%$ & 0.5 & $74.3 \%$ & $92.9 \%$ & 0.38 \\
\hline 5 year disease free survival & $73.3 \%$ & $62.5 \%$ & 0.27 & $46.9 \%$ & $51.9 \%$ & 0.52
\end{tabular}

EBRT - external beam radiotherapy

compared to combined brachytherapy and EBRT group $(81.7 \%$ vs. $62.5 \% ; p=0.04)$, however no significant difference was found between the NCR and DFS among the two groups. For T2 stage, patients treated with combined brachytherapy and EBRT had higher 5 year NCR and DFS rates than patients treated with brachytherapy alone (NCR: $92.9 \%$ vs. $74.3 \%$; DFS: $51.9 \%$ vs. $46.9 \%$ ), though the difference was not statistically significant.

As discussed previously in methodology, among the 62 patients treated by primary brachytherapy, 8 patients (T1 stage $=1$ patient and T2 stage $=7$ patients) had already undergone wide local excision and neck dissection as pri- mary treatment at some other institute, and due to focal margin positivity in the primary tongue region, were treated by interstitial brachytherapy (as radical treatment) for the primary site at our institute. Out of these 8 patients, 2 patients with initial stage T2 failed treatment, one at local site, the other at both local and nodal sites.

\section{Prognostic factors for recurrence}

Table 6 shows the prognostic factors related to local and nodal control. Higher T stage is significantly correlated to local failure as determined by univariate analysis, while by multivariate analysis, higher $\mathrm{T}$ stage and the 
Table 6. Prognostic factors related to local and nodal failure

\begin{tabular}{|c|c|c|c|c|c|c|}
\hline Prognostic factors & $\begin{array}{l}\text { Local failures in this } \\
\text { group/total patients } \\
\text { in this group (\%) }\end{array}$ & Univariate & Multivariate & $\begin{array}{l}\text { Nodal failures in this } \\
\text { group/ total patients } \\
\text { in this group (\%) }\end{array}$ & Univariate & Multivariate \\
\hline \multicolumn{7}{|l|}{ Age } \\
\hline$>60 \mathrm{yrs}$ & $12 / 29(41.4 \%)$ & \multirow[t]{2}{*}{$p=0.79$} & \multirow[t]{2}{*}{$p=0.87$} & $5 / 29(17.2 \%)$ & \multirow[t]{2}{*}{$p=0.8$} & \multirow[t]{2}{*}{$p=0.99$} \\
\hline$<60$ yrs & 23/63 (36.5\%) & & & 10/63 (15.9\%) & & \\
\hline \multicolumn{7}{|l|}{ Sex } \\
\hline Male & 25/64 (39.1\%) & \multirow[t]{2}{*}{$p=0.71$} & \multirow[t]{2}{*}{$p=0.64$} & 11/64 (17.2\%) & \multirow[t]{2}{*}{$p=0.58$} & \multirow[t]{2}{*}{$p=0.54$} \\
\hline Female & $10 / 28(35.7 \%)$ & & & 4/28 (14.3\%) & & \\
\hline \multicolumn{7}{|l|}{ Stage } \\
\hline $\mathrm{T} 1$ & $14 / 47(29.8 \%)$ & \multirow[t]{2}{*}{$p=0.02$} & \multirow[t]{2}{*}{$p=0.009$} & $7 / 47$ (14.9\%) & \multirow[t]{2}{*}{$p=0.43$} & \multirow[t]{2}{*}{$p=0.22$} \\
\hline $\mathrm{T} 2$ & $21 / 45(46.7 \%)$ & & & $8 / 45(17.8 \%)$ & & \\
\hline \multicolumn{7}{|l|}{ Tumor thickness } \\
\hline$<1 \mathrm{~cm}$ & $17 / 50(34 \%)$ & \multirow[t]{2}{*}{$p=0.09$} & \multirow[t]{2}{*}{$p=0.35$} & $7 / 50(14 \%)$ & \multirow[t]{2}{*}{$p=0.37$} & \multirow[t]{2}{*}{$p=0.43$} \\
\hline$\geq 1 \mathrm{~cm}$ & $18 / 42(42.9 \%)$ & & & $8 / 42(19 \%)$ & & \\
\hline \multicolumn{7}{|c|}{ EBRT + brachytherapy } \\
\hline Yes & $14 / 30(46.7 \%)$ & \multirow[t]{2}{*}{$p=0.18$} & \multirow[t]{2}{*}{$p=0.02$} & 4/30 (13.3\%) & \multirow[t]{2}{*}{$p=0.6$} & \multirow[t]{2}{*}{$p=0.92$} \\
\hline No & $21 / 62(33.9 \%)$ & & & $11 / 62(17.7 \%)$ & & \\
\hline \multicolumn{7}{|l|}{ Implant } \\
\hline Single plane & 19/50 (38\%) & \multirow[t]{2}{*}{$p=0.8$} & \multirow[t]{2}{*}{$p=0.52$} & $7 / 50$ (14\%) & \multirow[t]{2}{*}{$p=0.65$} & \multirow[t]{2}{*}{$p=0.41$} \\
\hline Double plane & $16 / 42(38.1 \%)$ & & & $8 / 42(19 \%)$ & & \\
\hline
\end{tabular}

addition of EBRT prior to brachytherapy correlate significantly to local failure. None of the patient or treatment factors were found significantly prognostic for nodal control by both univariate and multivariate analysis.

In subset analysis, for T1 stage alone, addition of EBRT to brachytherapy is a poor prognostic factor for local control, both by univariate $(p=0.02)$ and multivariate analysis $(p=0.04)$. However, for T2 stage, none of the factors were found prognostic for local or nodal control.

\section{Acute toxicity and the correlation to biological equivalent dose}

Table 7 shows the details of acute toxicities experienced by patients 2 weeks post brachytherapy. No patient developed grade 4 mucositis. There is significant difference in the incidence of acute mucositis (grade $\geq 2$ ) between the brachytherapy alone group (54 out of 62 patients $=87 \%$ ) and the combined modality group ( 20 out of 30 patients $=66 \%)$. This difference can be attributed to the difference in BED among the two arms $(p=0.02)$ (Table 8).

\section{Late toxicity}

Table 7 determines the late toxicities experienced by patients. Sixty-one patients $(66.3 \%)$ did not experience any significant late complication. In our patients, the incidence of late complications was not correlated to BED among the two groups (Table 8).

\section{Attempt to salvage therapy}

Out of 28 patients who had local recurrence alone, 11 patients had prior stage T1N0M0, and 17 patients had stage T2N0M0. On local recurrence, 14 patients did not undergo any treatment and were lost to follow up. Out of the rest 14 patients, 4 underwent surgery with or without post op radiotherapy (wide local excision (WLE) in 1 patient, WLE + neck dissection, and post op EBRT in 2 patients, total glossectomy in 1 patient), and 2 patients underwent chemoradiation to the dose of $60 \mathrm{~Gy}$ in 30 fractions in 6 weeks. All these 6 patients were asymptomatic till the last date of follow up. Rest 8 patients, despite being treated with surgery or EBRT (depending upon previous treatment), failed to achieve disease free status at their last follow up.

Out of 8 patients with nodal recurrence alone, 4 patients had prior stage T1N0M0 and other 4 had stage T2N0M0. None of these 8 patients had received EBRT in their initial management. Therefore, neck was not addressed previously in any of these patients. The distribution of lymph node recurrence involved ipsilateral upper jugular and middle jugular. As a salvage treatment, three patients had undergone neck dissection followed by post-operative radiotherapy, three had undergone chemoradiation to the dose of 45 Gy delivered in 25 fractions to the local and nodal site, as neck dissection was not feasible in these patients in view of hard fixed lymph 
nodes. The last two were sent for surgery but were lost to follow up. Five patients who were treated post nodal recurrence, remained disease free till their last date of follow up in this analysis. Only one patient died of lymph node and distant metastases despite salvage neck dissection along with EBRT.

Table 7. Acute and late complications

\begin{tabular}{|c|c|}
\hline Acute mucositis at week 2 & Number of patients \\
\hline \multicolumn{2}{|l|}{ Grade } \\
\hline 0 & $9(9.8 \%)$ \\
\hline 1 & $9(9.8 \%)$ \\
\hline 2 & $48(52.2 \%)$ \\
\hline 3 & $26(28.3 \%)$ \\
\hline Late complications & Number of patients \\
\hline Nil & $61(66.3 \%)$ \\
\hline \multicolumn{2}{|l|}{ Chronic pain } \\
\hline Grade 2 & $4(4.3 \%)$ \\
\hline Grade 3 & 0 \\
\hline \multicolumn{2}{|l|}{ Xerostomia } \\
\hline Grade 2 & 1 (1.1\%) \\
\hline Grade 3 & 0 \\
\hline \multicolumn{2}{|l|}{ Trismus } \\
\hline Grade 2 & $4(4.3 \%)$ \\
\hline Grade 3 & 0 \\
\hline \multicolumn{2}{|l|}{ Ankyloglossia } \\
\hline Grade 2 & $4(4.3 \%)$ \\
\hline Grade 3 & $3(3.3 \%)$ \\
\hline \multicolumn{2}{|l|}{ Taste changes } \\
\hline Grade 2 & $2(2.2 \%)$ \\
\hline Grade 3 & 0 \\
\hline \multicolumn{2}{|l|}{ Induration } \\
\hline Grade 2 & $10(10.9 \%)$ \\
\hline Grade 3 & $2(2.2 \%)$ \\
\hline \multicolumn{2}{|l|}{ Osteoradionecrosis } \\
\hline Grade 3 & $1(1.1 \%)$ \\
\hline
\end{tabular}

Seven patients had failed both at local and nodal site. Out of these 7 , three patients underwent surgery with or without EBRT and were disease free at the time of last follow up; 1 had persistent disease despite surgery for primary and nodal site and post op radiotherapy, and 3 patients were lost to follow up.

\section{Functional outcome}

The functional outcome of the patient was evaluated based on the records available regarding the ability to eat a regular diet and the understandability of speech. The case records of all 92 patients in this study were retrospectively studied and based on the performance scale followed at our institute for the head and neck cancer patients, the functional outcome was analyzed (Table 9). Almost $97 \%$ patients had a preserved tongue function in terms of good understandability of speech and $93 \%$ approximately had maintained the normality of their diet.

\section{Discussion}

For oral tongue carcinomas, surgery and radiotherapy are the standard of care $[19,20]$. But for early stage tongue cancers (stage I and II), interstitial brachytherapy is also considered an effective treatment modality as local control and survival results are equivalent to that of surgery $[1,3]$. Also, with brachytherapy, there is an added advantage of functional preservation of tongue. Some authors have used brachytherapy as a boost to EBRT especially in those early stage patients who have higher risk factors and are not suitable for brachytherapy as the sole treatment [21,22].

At our institute, patients with early stage oral tongue cancers were treated via brachytherapy alone or as a boost to EBRT. The clinical outcome in terms of loco regional control rates and survival has been compared among the two groups in this study. The 5-year LCR of $64.2 \%$ seen in our patients, was quite lower than the rates reported in literature $[2,6,12,13]$. On subset analysis according to T stage, the 5 year LCR for stage I and stage II were $74.7 \%$ and $52.5 \%$, respectively, which are again inferior compared to the previous reports $[13,14,15,16]$. To determine possible reasons for these inferior results, stage wise LCR and survival rates were analyzed in terms of prior EBRT given or not. We found that for T1 stage, LCR were higher in patients treated with brachytherapy alone, compared to those treated with EBRT prior to brachytherapy boost $(p=0.04)$. The local failures were 6 out of 31 cases $(19 \%)$ by brachytherapy alone, and 8 out of 16 cases (50\%) by EBRT with brachytherapy. This can be explained by different

Table 8. Correlation of acute mucositis and biological equivalent dose (BED)

\begin{tabular}{lccc} 
& $\begin{array}{c}\text { Brachytherapy alone } \\
(n, \%)\end{array}$ & $\begin{array}{c}\text { EBRT + brachytherapy } \\
(n, \%)\end{array}$ & Pearson's correlation \\
\hline Acute mucositis $\geq 2$ & $\mathrm{BED}_{10}=72.8 \mathrm{~Gy}$ & $\mathrm{BED}_{10}=65.8 \mathrm{~Gy}$ & $p=0.02$ \\
& $54 / 62 ; 87 \%$ & $20 / 30 ; 66 \%$ & $p=0.96$
\end{tabular}

$B E D_{10}$ - biological equivalent dose for acute toxicity; $B E D_{3}$ - biological equivalent dose for late toxicity; $E B R T$ - external beam radiotherapy 
Table 9. Performance scale for analyzing functional status in head and neck cancer patients

\begin{tabular}{|c|c|c|c|}
\hline Performance & Scale & Score & Number of patients (\%) \\
\hline \multirow[t]{3}{*}{ Normalcy of diet } & No restriction in diet & Good & 85 (92.39\%) \\
\hline & Soft, semisolid diet only & Average & $7(7.61 \%)$ \\
\hline & Liquids only/on tube feeding & Poor & 0 \\
\hline \multirow[t]{3}{*}{ Understandability of speech } & Completely understandable & Good & $89(96.73 \%)$ \\
\hline & Difficult to understand/repetition necessary & Average & $3(3.26 \%)$ \\
\hline & Not understood & Poor & 0 \\
\hline
\end{tabular}

biologically equivalent doses (BEDs) achieved in the two groups. The $\mathrm{BED}_{10}$ for tumor for the brachytherapy alone group ranged from 56 Gy to 72.8 Gy (average $=64.4 \mathrm{~Gy}$ ) but for combined EBRT and brachytherapy boost group, it ranged from $58.31 \mathrm{~Gy}$ to $65.34 \mathrm{~Gy}$ (average $=61.82 \mathrm{~Gy}$ ), as calculated by using the linear-quadratic model equation number 1.7 given by Fowler et al. [23,24,25], by applying corrections for overall treatment time: $\mathrm{T}=38$ or 39 days $=28$ days EBRT, 3 or 4 days brachytherapy boost $(3$ days when 18 Gy boost given in 3 days, and 4 days when $24 \mathrm{~Gy}$ boost given in 4 days), and 7 days gap prior to brachytherapy for mucosal reactions to heal), starting time of tumor repopulation $(\mathrm{Tk}=21$ days $)$ and cell population doubling time during treatment done by EBRT and brachytherapy boost $(\mathrm{Tp}=3$ days):

$\mathrm{BED}=\mathrm{nd}\left(1+\frac{\mathrm{d}}{\alpha / \beta}\right)-\frac{0.693\left(\mathrm{~T}-\mathrm{T}_{\mathrm{k}}\right)}{\alpha \mathrm{Tp}} \quad$ [Equation 1.7] [2

For head and neck tumors, $\alpha / \beta$ was taken as 10 .

This paradoxical result might also have derived from the bias that patients treated with combined therapy had more risk factors in terms of tumor thickness, lymphovascular emboli, and perineural invasion, and some of these factors could not be analyzed adequately in view of retrospective nature of our study.

But when T2 stage patients were analyzed, it was found that the local failures were 15 out of 31 cases (48\%) by brachytherapy alone and 6 out of 14 cases $(43 \%)$ by EBRT with brachytherapy. Therefore, not only combined modality but brachytherapy alone also brought out a negative result in terms of local control rate in T2 stage patients. These numbers indicate that even $\mathrm{BED}_{10}$ of 72.8 Gy (achieved by brachytherapy alone) is inadequate for the local control of T2 tumors. This signifies that there is a need for dose escalation for primary lesion by combined EBRT with brachytherapy boost in both T1 and T2 stage patients and also, by brachytherapy alone in T2 stage patients. The results of this study are in contradiction to the dose reduction trials conducted by various authors [26,27], who consider 54 Gy in 9 fractions over 7 days as a feasible treatment to reduce patient discomfort in mobile tongue cancer patients, compared to $60 \mathrm{~Gy}$ in 10 fractions.

Various authors have demonstrated local control rates ranging from 90 to $100 \%$ by using equivalent doses from 65 to $80 \mathrm{~Gy}$ in oral cavity tumors $[28,29,30]$. In our insti- tute, in order to decrease acute and late complications, the dose per fraction and the total dose were compromised in both brachytherapy alone as well as combined schedules. The maximum equivalent dose achieved by brachytherapy alone in our study was $60.66 \mathrm{~Gy}$ only. This might explain the inferior local control results in T1 stage patients in our study compared to the results in literature.

Local control rates and BED are known to be related [31]. Therefore, a conclusion of local/loco-regional control rate from the two treatment techniques (brachytherapy alone and combined EBRT and brachytherapy boost) based on different BEDs setup may be questionable. But it is important to understand that the highlight of the study was not only to compare the different loco regional control rates and BEDs of two radiation schedules, but to convey an important conclusion that dose escalation (from the doses used in study) is needed in both $\mathrm{T} 1$ and T2 stage patients whether brachytherapy is used as sole modality or as boost. Also, while calculating total BED, corrections need to be applied for overall treatment time, tumor repopulation, and cell population doubling time during treatment done by EBRT and brachytherapy boost.

In contrast to the LCR, the nodal failure rates in our patients treated with brachytherapy were quite low compared to the reports of $20-50 \%$ in literature $[2,5,10,14,16]$. The 3- and 5-year nodal failure rates were $14.6 \%$ and $16.2 \%$, respectively. The good nodal control rates achieved by our patients could be due to the fact that all these early stage patients were not treated by brachytherapy alone. Some patients with poor prognostic factors for local/nodal recurrence had also undergone either prior surgery in the form of neck dissection $(8$ patients $=$ $8.7 \%$ ) or EBRT prior to brachytherapy boost (30 patients $=32.6 \%$ ). This could have contributed to better nodal control rates achieved by our patients. This improvement may also be in part due to the development of better imaging modalities in the neck evaluation in tongue cancer patients compared to the past, leading to better selection of node negative early stage patients.

Coming to the results of NCR for T1 stage in both the groups, there was no significant difference in the results whether patients received prior EBRT or not. This signifies that brachytherapy alone is sufficient for T1 stage patients, and neck addressal is not required for these patients. The similar results have been described by various studies in literature too $[1,3,4,6,10]$. 
For T2 stage, the 5 year NCR were higher in the combined EBRT and brachytherapy group compared to brachytherapy alone group $(92.9 \%$ vs. $74.3 \%)$ but the results could not achieve statistical significance. While analyzing the patients in these two groups, it was found that 7 out of 8 patients in brachytherapy alone group had already undergone neck dissection, thereby diluting the actual results. Therefore, another analysis was done in the two groups in T2 stage patients, based upon neck nodes addressed (either by neck dissection, EBRT, or both) or not addressed. The 5 year NCR in 21 patients in whom neck was addressed was $85.7 \%$, and in 24 patients in whom neck was not addressed it was $71.8 \%$, and the results were statistically significant $(p=0.02)$. This highlights the need and benefit to treat T2 stage patients with combined modality to achieve higher nodal control rates.

Regarding the prognostic factors, higher T stage and use of combined modality (EBRT with brachytherapy) were the only factors found to be prognostic for poor local control. No other factor was found prognostic for nodal control. Although several authors have reported tumor thickness > 5-6 $\mathrm{mm}$ and ulcerative/infiltrative types of tumors to be poor prognostic factor for lymph node metastasis [32,33], our study failed to demonstrate this. This is because our reporting of tumor thickness was mostly clinical and could specify it to be more or less than $1 \mathrm{~cm}$. Another factor responsible is inadequate reporting of tumor thickness in biopsy specimens, and also, MRI (magnetic resonance imaging) scans were not done before interstitial implants, especially in patients treated in earlier years of this study. This was one of the limitations of our study.

In our series, acute complications post 6 weeks of brachytherapy were well tolerable and within the acceptable limits. The late complications were seen in $32.9 \%$ of patients, however out of these, grade 3 complications in terms of induration, ankyloglossia, and bone necrosis were seen in 6 patients $(6.5 \%)$ only. The complication rate is similar to the grade 3 complication rates of 3-15\% mentioned in literature $[4,5,6,10,34]$. However, no correlation was found between the incidence of late complications and the BED of the two groups. This is in contrast to the study by Kehwar [35], who suggested that the probability of late complication is directly related to radiation dose received. One of the reasons for few severe late complications observed in our patients may be the insufficient dose used for primary lesion as described above. Since dose escalation is the necessity to achieve better control rates, late complications in terms of mandibular necrosis can still be prevented by using spacer or blocker in routine practice.

The functional outcome for our patients was assessed by using a performance scale to evaluate adequacy of diet and speech. Most of the patients scored well. Many authors previously also have analyzed quality of life of patients post brachytherapy and have found that majority of patients could maintain their pre-diagnosis nutritional status and speech $[36,37]$.

The dosimetric and volumetric parameters of interest reflecting the quality of treatment are beyond the scope of this article, as this study is mainly concerned with de- scribing the clinical outcome of the patients treated with interstitial implant. The dosimetric results will be described in detail in subsequent study.

\section{Conclusions}

Although this study is retrospective, the results are noteworthy, considering its long follow up and the description of results in terms of LCR, toxicities, and functional outcome. Our study recommends treating patients with brachytherapy alone in T1 stage and demonstrates the need for addressing nodal region either by neck dissection or nodal irradiation in T2 stage patients. The highlight of the study is that it establishes the need for dose escalation (from the doses used in the study) in both T1 and T2 stage tumors when using interstitial brachytherapy either as sole modality or as a boost.

\section{Disclosure}

Authors report no conflict of interest.

\section{References}

1. Matsuura K, Hirokawa Y, Fujita M et al. Treatment results of stage I and II oral tongue cancer with interstitial brachytherapy: maximum tumor thickness is prognostic of nodal metastasis. Int J Radiat Oncol Biol Phys 1998; 40: 535-539.

2. Perez CA, Brady LW, Halperin EC. Principles and Practice of Radiation Oncology. $4^{\text {th }}$ ed. Lippincott Williams and Wilkins, Philadelphia 2004; 1005.

3. Nakagawa T, Shibuya H, Yoshimura R et al. Neck node metastasis after successful brachytherapy for early stage tongue carcinoma. Radiother Oncol 2003; 68: 129-135.

4. Mazeron JJ, Crook JM, Benck V et al. Iridium 192 implantation of T1and T2 carcinomas of mobile tongue. Int J Radiat Oncol Biol Phys 1990; 19: 1369-1376.

5. Shibuya H, Hoshina M, Takeda M et al. Brachytherapy for Stage I and II oral tongue cancer: an analysis of past cases focusing on control and complications. Int J Radiat Oncol Biol Phys 1993; 26: 51-58.

6. Bachaud JM, Delannes M, Allouache N et al. Radiotherapy of stage I and II carcinomas of the mobile tongue and/or floor of the mouth. Radiother Oncol 1994; 31: 199-206.

7. Yamazaki H, Inoue T, Yoshida K et al. Brachytherapy for early oral tongue cancer: low dose rate to high dose rate. J Radiat Res 2003; 44: 37-40.

8. Oota S, Shibuya H, Yoshimura R et al. Brachytherapy of stage II mobile tongue carcinoma. Prediction of local control and QOL. Radiat Oncol 2006; 1: 21.

9. Kobayashi Y, Karasawa K, Komiya Y et al. Therapeutic results for 100 patients with cancer of the mobile tongue treated with low dose rate Interstitial Irradiation. Anticancer Research 2007; 27: 1689-1692.

10. Bhalavat RL, Mahantshetty UM, Tole S et al. Treatment outcome with low-dose-rate interstitial brachytherapy in early-stage oral tongue cancers. J Cancer Res Ther 2009; 5: 192-197.

11. Petera J, Doležel M, Jirousek $Z$ et al. High dose rate brachytherapy in the treatment of oral cancer - the preliminary one institution experience. Neoplasma 2006; 53: 232-236.

12. Kakimoto $\mathrm{N}$, Inoue $\mathrm{T}$, Inoue $\mathrm{T}$ et al. High-dose-rate interstitial brachytherapy for mobile tongue cancer: influence of the non-irradiated period. Anticancer Res 2006; 26: 3933-3937.

13. Tuček L, Petera J, Sirák I et al. Hyperfractionated high-dose rate brachytherapy in the treatment of oral tongue cancer. Rep Pract Oncol Radiother 2011; 16: 243-247. 
14. Matsumoto K, Sasaki T, Shioyama Y et al. Treatment outcome of high-dose-rate interstitial radiation therapy for patients with stage I and II mobile tongue cancer. Jpn J Clin Oncol 2013; 43: 1012-1017.

15. Akiyama H, Yoshida K, Shimizutani K et al. Dose reduction trial from 60 Gy in 10 fractions to 54 Gy in 9 fractions schedule in high-dose-rate interstitial brachytherapy for early oral tongue cancer. J Radiat Res 2012; 53: 722-726.

16. Urashima Y, Nakamura K, Kunitake N et al. Is glossectomy necessary for late nodal metastases without clinical local recurrence after initial brachytherapy for N0 tongue cancer? A retrospective experience in 111 patients who received salvage therapy for cervical failure. Jpn J Clin Oncol 2006; 36: 3-6.

17. Pierquin B, Dutreix A, Paine $\mathrm{CH}$ et al. The Paris system in interstitial radiation therapy. Acta Radiol Oncol Radiat Phys Biol 1978; 17: 33-48.

18. Nag S, Cano ER, Demanes DJ et al. The American Brachytherapy Society recommendations for high-dose-rate brachytherapy for head-and-neck carcinoma. Int J Radiat Oncol Biol Phys 2001; 50: 1190-1198.

19. Omura K. Current status of oral cancer treatment strategies: surgical treatments for oral squamous cell carcinoma. Int J Clin Oncol 2014; 19: 423-430.

20. Sharma P, Shah SV, Taneja C et al. A prospective study of prognostic factors for recurrence in early oral tongue cancer. J Clin Diagn Res 2013; 7: 2559-2562.

21. Bolner A, Campolongo F, Segatta P et al. Brachytherapy in the management of the initial stage of the mobile tongue carcinoma. Acta Otorhinolaryngol Ital 1999; 19: 80-86.

22. Wendt CD, Peters LJ, Delclos L et al. Primary radiotherapy in the treatment of stage I and II oral tongue cancers: importance of the proportion of therapy delivered with interstitial therapy. Int J Radiat Oncol Biol Phys 1990; 18: 1287-1292.

23. Fowler JF, Lindstrom MJ. Loss of local control with prolongation in radiotherapy. Int J Radiat Oncol Biol Phys 1992; 23. 457-467.

24. Fowler JF. The linear-quadratic formula and progress in fractionated radiotherapy. Br J Radiol 1989; 62: 679-694.

25. Fowler JF. practical time-dose evaluations, or how to stop worrying and learn to love linear quadratics. In: Levitt $\mathrm{SH}$ Purdy JA, Perez CA, Vijaykumar S. Technical Basis of Radiation Therapy: Practical Clinical Applications. $4^{\text {th }}$ ed. SpringerVerlag, Berlin Heidelberg 2006; 13.

26. Okamoto T, Akiyama H, Gamoh S et al. High-dose-rate interstitial brachytherapy for tongue cancer; a radiological and biological study from the perspective of late complications. J Osaka Dent Univ 2012; 46: 57-62.

27. Akiyama H, Yoshida K, Yamazaki $\mathrm{H}$ et al. High-dose-rate interstitial brachytherapy for mobile tongue cancer: preliminary results of a dose reduction trial. J Contemp Brachytherapy 2014; 6: 10-14.

28. Donath D, Vuong T, Shnouda G, et al. The potential uses of high-dose-rate brachytherapy in patients with head and neck cancer. Eur Arch Otorhinolaryngol 1995; 252: 321-354.

29. Inoue $\mathrm{T}$, Inoue $\mathrm{T}$, Teshima $\mathrm{T}$ et al. Phase III trial of high and low dose rate interstitial radiotherapy for early oral tongue cancer. Int J Radiat Oncol Biol Phys 1996; 36: 1201-1204.

30. Leung TW, Wong VYW, Wong CM et al. Technical hints for high dose rate interstitial tongue brachytherapy. Clin Oncol (R Coll Radiol) 1998; 10: 231-236.

31. Sharma B, Singh T, Singh T. Evaluation of variation in dose of organs at risk in intracavitary brachytherapy of cervical cancer - a prospective study. I Contemp Brachyther 2011; 3: 23-25.

32. Yamazaki $\mathrm{H}$, Inoue $\mathrm{T}$, Yoshida $\mathrm{K}$ et al. Lymph node metastasis of early oral tongue cancer after interstitial radiotherapy. Int J Radiat Oncol Biol Phys 2004; 58: 139-146.
33. Ichimiya $Y$, Fuwa N, Kamata M et al. Treatment results of stage I oral tongue cancer with definitive radiotherapy. Oral Oncol 2005; 4: 520-525.

34. Simha V, Sharma SC, Kapoor R et al. Evaluation of neuropathic pain occurring after high-dose-rate interstitial brachytherapy of oral tongue. J Contemp Brachytherapy 2015; 7: 142146.

35. Kehwar TS. Analytical approach to estimate normal tissue complication probability using best fit of normal tissue tolerance doses into the NTCP equation of the linear quadratic model. J Cancer Res Therapeut 2005; 1: 168-179.

36. Harrison LB, Zelefsky MJ, Pfister DG et al. Detailed quality of life assessment in patients treated with primary radiotherapy for squamous cell cancer of the base of the tongue. Head Neck 1997; 19: 169-175.

37. Urashima Y, Nakamura K, Shioyama Y et al. Long-term functional outcome of brachytherapy for carcinoma of the mobile tongue: focus on the atrophic change of irradiated tongue. Jpn J Clin Oncol 2006; 36: 681-687. 